\title{
(6) OPEN ACCESS \\ Long-term effects of youth unemployment on mental health: does an economic crisis make a difference?
}

\author{
Emelie Thern, ${ }^{1}$ Jeroen de Munter, ${ }^{1}$ Tomas Hemmingsson, ${ }^{2,3}$ Finn Rasmussen ${ }^{1,4}$
}

\begin{abstract}
- Additional material is published online only. To view please visit the journal online (http://dx.doi.org/10.1136/ jech-2016-208012)

${ }^{1}$ Child and Adolescent Public Health Epidemiology Unit, Department of Public Health Sciences, Karolinska Institutet, Stockholm, Sweden UUnit of Occupational Medicine, Institute of Environmental Medicine, Karolinska Institutet, Stockholm, Sweden

${ }^{3}$ Centre for Social Research on Alcohol and Drugs, Stockholm University, Stockholm, Sweden ${ }^{4}$ Health Care Services, Centre for Epidemiology and Community Medicine, Stockholm County Council, Stockholm, Sweden
\end{abstract}

\section{Correspondence to}

Emelie Thern, Child and Adolescent Public Health Epidemiology Unit,

Department of Public Health Sciences, Karolinska Institutet, Tomtebodavägen 18A, Widerströmska huset, Stockholm 171 77, Sweden; emelie.thern@ki.se

Received 29 June 2016 Revised 23 November 2016 Accepted 29 December 2016 Published Online First 13 January 2017

\section{CrossMark}

To cite: Thern E, de Munter J, Hemmingsson $\mathrm{T}$, et al. J Epidemiol Community Health 2017:71:344-349.

\section{ABSTRACT}

Background III health is a risk factor and a consequence of unemployment, which might vary depending on the national rate of unemployment. We investigated the long-term effect of youth unemployment on mental health and explored the possible interaction during periods of high (economic crisis) and low (non-crisis) unemployment rates.

Methods A register-linked population-based cohort study was conducted including individuals aged 1724 years. The crisis cohort $(n=6410)$ took part in the Labour Force Survey during the economic crisis (1991$1994)$ in Sweden and the non-crisis cohort $(n=8162)$ took part in the same survey before the crisis (19831986). Follow-up was 19 years. Adjusted HRs and 95\% Cls for an inpatient care discharge mental diagnosis with employed people as the reference group were calculated by Cox regressions models.

Results In fully adjusted models, $<3$ months (HR: 1.69 ; $95 \%$ Cl 1.14 to 2.49$), 3-6$ months (2.19; 1.43 to 3.37 ) and $>6$ months (2.70; 1.71 to 4.28$)$ of unemployment were associated with increased risks of getting a mental diagnosis in the crisis cohort. In the non-crisis cohort the risks were: $1.92 ; 1.40$ to $2.63,2.60 ; 1.72$ to 3.94 and $3.33 ; 2.00$ to 5.57 , respectively. No interactions between labour force status and level of unemployment were found.

Conclusions Youth unemployment is related to mental health problems, independent of the overall national rate of unemployment, which is important as the youth unemployment rates are currently at stable high level.

\section{INTRODUCTION}

In the last decades, youth unemployment has become an increasing problem for many countries, including Sweden. ${ }^{1}$ Prior to 1991 , the Swedish youth unemployment was at a comparatively low stable level, around $5 \% .^{2}$ During the years of 1991-1994, Sweden suffered a deep economic crisis. $^{3} 4$ As a result, youth unemployment increased from $3.4 \%$ in 1990 to $19 \%$ in $1993 .^{34}$ Today, the Swedish youth unemployment rate is at a high stable rate, above $20 \% .^{5}$

Leaving school to find employment is a central and difficult transition for young people. ${ }^{3} 46$ An extensive body of literature suggests that youth unemployment is related to a decrease in physical and mental health and an increase in smoking and alcohol consumption. ${ }^{7-16}$ Further, youth appears to be a sensitive time period in life, as recent studies have found that the effect of youth unemployment on mental health remains in adulthood, independent of later unemployment experiences. ${ }^{6}{ }^{14-16}$ The relationship between unemployment and ill health is, however, more complex as the effect could differ depending on the national rate of unemployment.

There are several theoretical frameworks that could potentially explain the contextual influence on the association between unemployment and health. If the health effect of unemployment is stronger during periods of low unemployment then the association might be more confounded by health selection or unemployment might be more stigmatised. ${ }^{17} 18$ Alternatively, being unemployed during a period of high unemployment might buffer the negative consequences of unemployment as it is easier to attribute ones situation to external causes. ${ }^{19}$ Then again, high unemployment creates uncertainty among the unemployed about their possibilities on the labour market which could strengthen the effects of unemployment. ${ }^{19} 20$ There is, however, no consistent evidence in the current literature concerning the direction and magnitude of the influence of national rate of unemployment on the association between unemployment and mental health. ${ }^{17} 19$ 21-23

In addition, the national rate of unemployment might affect health differently in certain subgroups. The area of youth unemployment has received little attention with this regard. One previous study that attempted to examine the effects of health selection by comparing two time periods, did not find a difference in somatic and psychological symptoms among the long-term unemployed. ${ }^{21}$

Previous research on youth unemployment has to a great extent relied on self-reported measures to assess the health or health behaviours. ${ }^{13} 1924$ Thus, there is a need to include more severe health outcomes, such as hospital diagnoses to more comprehensively address the effects of youth unemployment on health later in life. ${ }^{13}$

The aims of the current study are (1) to investigate the effect of youth unemployment on mental health during periods of high and low unemployment rates and (2) to explore whether there is any interaction in mental health between labour force status and level of unemployment.

\section{METHODS}

Our population-based study is based on a data set created through record linkage of nationwide registers kept by Statistics Sweden and the National Board of Health and Welfare by using the Swedish unique personal identification number. Registers included are the Labour Force Survey (LFS), the National Population and Housing Censuses, The Cause of Death Register and National Hospital Discharge Register. ${ }^{25} 26$ 


\section{Sampling and study population}

The study was based on two separate cohorts who participated in the LFS between the ages of 17-24. The LFS is a telephonesupported interview. Included individuals are interviewed every 3 months for a total period of 2 years, resulting in eight different interviews regarding their current labour force status. ${ }^{2} 26$ The age span was selected since the majority have completed compulsory schooling by the age of 17 and the official upper limit of the Swedish definition of youth unemployment is 24 years. $^{27}$ Individuals that are registered in Sweden (aged 16$65)$ are randomly selected to participate in the LFS. ${ }^{26}$ The first cohort comprised all individuals born between 1969 and 1974 who completed the LFS during the period 1991-1994 $(n=7208)$, the 'crisis cohort'. The second cohort comprised all individuals born between 1961 and 1966 who completed the LFS during 1983-1986 ( $\mathrm{n}=9076)$, the 'non-crisis cohort'. To determine youth unemployment, we used several measurement points of the individuals' current labour force status, consequently individuals that had missing data on more than three out of the eight interviews from the LFS were excluded (please see supplementary figure $\mathrm{S} 1$ ).

\section{Exposure: employment status}

Information on employment status was collected from the LFS. The LFS divides the population into two main categories: individuals who are active in the labour force (ie, employed or unemployed) and individuals who are economically inactive (ie, students, conscripts, pensioners or individuals with long-term illness). The employed group consists of people who perform at least 1 hour of work each week. The unemployed group consists of people who work for $<1$ hour/week, actively looking for work and able to start a new job within 2 weeks of the interview. ${ }^{2} 26$

The study population was categorised into six mutually exclusive groups based on the LFS definitions: unemployed $<3$ months, unemployed 3-6 months, unemployed > 6 months, economically inactive, unstable labour force status and full-time employed (the reference group). Individuals reporting being unemployed during one interview were categorised as $<3$ months unemployment, reporting being unemployed in two consecutive interviews were categorised as 3-6 months of unemployment and for three or more consecutive interviews were categorised as $>6$ months of unemployment. Individuals defined as being economically inactive for at least five of the eight interviews were categorised into this group. Individuals with a combination of labour force status or working part-time ( $<35$ hours/week) were categorised as having an unstable labour force status. Individuals defined as employed and working 35 hours/week or more for at least five out of the eight interviews were defined as being full-time employed.

\section{Outcome measure: mental diagnosis}

Diagnosis of mental health, according to the Swedish version of the International Statistical Classification of Disease (ICD) versions 9 and 10 was collected from the National Hospital Discharge Register. The outcome of mental diagnosis was defined through four categories of discharge diagnosis: alcohol or drug use disorders (ICD-9: 291, 292, 303-305; ICD-10: F10-F19), affective disorders (mood disorders) (ICD-9: 296, 311; ICD-10: F30-F39), nervous or stress-related disorders (ICD-9: 300, 306, 308, 309; ICD-10: F40-F48) and self-harm (ICD-9: E950-E959, E980-E989; ICD-10: X60-X84, Y10Y34). Only first-time admissions were of interest during follow-up. The individual was considered as having the outcome of interest, if they had any of the diagnoses as either a principal or secondary discharge diagnosis.

\section{Covariates}

The analyses were controlled for the following individual factors: sex, age (continuous), country of birth and prior mental diagnosis (before 1991 in crisis cohort and 1983 in the noncrisis cohort). In addition to the mental diagnosis chosen as the outcome, we included diagnosis of organic psychosis, schizophrenia, other non-affective disorders, personality disorders, childhood mental disorders and mental retardation as covariates (ICD-8: 292, 293, 294, 294.4, 294.8-9, 295, 297, 298, 301, 302, 306, 308-315 and the corresponding ICD-9 codes).

The Multi-Generation Register (MGR), which contains information on all individuals registered in Sweden, was used to identify the individual's biological parents. ${ }^{28}$ The analyses were controlled for the following parental risk factors that were obtained at baseline: highest level of parent's education, socioeconomic index (SEI) and any of the parents registered inpatient care or cause of death due a mental diagnosis. The covariates were categorised as indicated in table $1 \mathrm{~A}, \mathrm{~B}$.

\section{Statistical analysis}

The analyses were stratified by cohort. HRs with 95\% CIs were obtained by Cox proportional hazard regression analysis after verification of the proportional hazards assumption using loglog plots and plots of Schoenfeld residuals. Person-time was calculated from the end of the exposure window (crisis cohort: 1 January 1995; non-crisis cohort: 1 January 1986) until first date of a mental diagnosis, emigration, death or until end of follow-up (crisis cohort: 31 December 2012; non-crisis cohort; 31 December 2004).

Evidence of an interaction between labour force status and sex, as well as labour force status and level of unemployment, was assessed by fitting the regression models with and without the interaction term and performing a likelihood ratio test. In a sensitivity analysis, we excluded individuals with prior mental health problems to assess potential bias due to reverse causality. Additional analysis was conducted in order to explore relationship between youth unemployment and specific mental diagnoses. Missing values were coded as separate categories. All analyses were computed using Stata Statistical Software: Release 13.

\section{RESULTS}

The final sample consisted of 6410 participants in the crisis cohort and 8162 in the non-crisis cohort. In both cohorts, individuals excluded were more likely to be male and born outside of Sweden compared with the included individuals. Similar prevalence of prior mental health problems was found among the included and excluded individuals.

\section{Descriptive characteristics}

Table 1A, B presents the study population of the crisis and noncrisis cohort. A larger proportion of individuals were defined as unemployed in the crisis cohort compared with the non-crisis cohort, consequently there was a smaller proportion of full-time employed in the crisis cohort.

The parents of the unemployed individuals had worse mental health compared with the other groups. Generally, a higher prevalence of prior mental health problems was found among the unemployed individuals in both cohorts compared with the other groups. Furthermore, in the non-crisis cohort a larger proportion of unemployed individuals were not born in Sweden compared with the other groups. 
Table 1 Baseline characteristics of the study population that participated in the Labour Force Survey in 1991-1994 for the crisis cohort and 1983-1986 for the non-crisis cohort among male and female individuals 17-24 years of age

\begin{tabular}{|c|c|c|c|c|c|c|c|}
\hline & \multirow[b]{2}{*}{$\begin{array}{l}\text { All unemployed } \\
\mathrm{N}(\%)\end{array}$} & \multicolumn{3}{|l|}{ Unemployed } & \multirow{2}{*}{$\begin{array}{l}\text { Economically inactive } \\
\mathrm{N}(\%)\end{array}$} & \multirow{2}{*}{$\begin{array}{l}\text { Unstable labour } \\
\text { force status } \\
\mathrm{N}(\%)\end{array}$} & \multirow{2}{*}{$\begin{array}{l}\text { Full-time employed } \\
\text { N (\%) }\end{array}$} \\
\hline & & $\begin{array}{l}<3 \text { months } \\
\mathrm{N}(\%)\end{array}$ & $\begin{array}{l}\text { 3-6 months } \\
\mathrm{N}(\%)\end{array}$ & $\begin{array}{l}>6 \text { months } \\
\mathrm{N}(\%)\end{array}$ & & & \\
\hline \multicolumn{8}{|l|}{ Crisis $(n=6410)$} \\
\hline $\mathrm{n}$ & $2170(33.9)$ & $1220(19.0)$ & $596(9.3)$ & $354(5.5)$ & $1418(22.1)$ & $1124(17.5)$ & $1698(26.5)$ \\
\hline \multicolumn{8}{|l|}{ Sex } \\
\hline Male & $1262(58.2)$ & 678 (55.6) & $351(58.9)$ & $233(65.8)$ & $695(49.0)$ & 376 (33.5) & $934(55.0)$ \\
\hline Female & $908(41.8)$ & $543(44.4)$ & $245(41.1)$ & $121(34.2)$ & $723(51.0)$ & 748 (66.6) & $764(45.0)$ \\
\hline Minimum age at first LFS interview* & $19.6 \pm 1.6$ & $19.5 \pm 1.6$ & $19.7 \pm 1.5$ & $20.0 \pm 1.5$ & $19.0 \pm 1.6$ & $19.3 \pm 1.6$ & $20.4 \pm 1.4$ \\
\hline \multicolumn{8}{|l|}{ Country of birth } \\
\hline Sweden & $2023(93.2)$ & 1138 (93.3) & $552(92.6)$ & 333 (94.1) & $1306(92.1)$ & 1061 (94.4) & 1599 (94.2) \\
\hline Other & $147(6.8)$ & $82(6.7)$ & $44(7.4)$ & $21(5.9)$ & $112(7.9)$ & $63(5.6)$ & $99(5.8)$ \\
\hline \multicolumn{8}{|l|}{ Parental education } \\
\hline Primary & $644(29.7)$ & $332(27.2)$ & 199 (33.4) & $113(31.9)$ & $242(17.1)$ & $255(22.7)$ & $556(32.7)$ \\
\hline Secondary & $938(43.2)$ & 495 (40.6) & $275(46.1)$ & $168(47.5)$ & $460(32.4)$ & $446(39.7)$ & $708(41.7)$ \\
\hline University and above & $519(23.9)$ & $354(29.0)$ & 105 (17.6) & $60(17.0)$ & $651(45.9)$ & $390(34.7)$ & $385(22.7)$ \\
\hline Missing & $69(3.2)$ & $39(3.2)$ & $17(2.9)$ & $13(3.7)$ & $65(4.6)$ & $33(2.9)$ & $49(2.9)$ \\
\hline \multicolumn{8}{|l|}{ Parental SEI } \\
\hline High non-manual & $306(14.1)$ & $213(17.5)$ & $61(10.2)$ & $32(9.0)$ & $438(20.9)$ & $250(22.2)$ & $249(14.7)$ \\
\hline Middle non-manual & $448(20.7)$ & $273(22.4)$ & $108(18.1)$ & $67(18.9)$ & 344 (24.6) & $275(24.5)$ & $355(20.9)$ \\
\hline Low non-manual & $351(16.2)$ & $183(14.0)$ & $107(18.0)$ & $61(17.2)$ & $170(12.0)$ & $168(15.0)$ & $302(17.8)$ \\
\hline Self-employed/farmer & $135(6.2)$ & $78(6.4)$ & $39(6.5)$ & $17(4.8)$ & $74(5.2)$ & $88(7.8)$ & $140(8.2)$ \\
\hline Skilled workers & 355 (16.4) & $180(14.8)$ & $114(19.1)$ & $61(17.2)$ & $139(9.8)$ & 139 (12.4) & 266 (15.6) \\
\hline Unskilled workers & $383(17.7)$ & $193(15.8)$ & $119(20.0)$ & $71(20.1)$ & $121(8.5)$ & $128(11.4)$ & $269(15.8)$ \\
\hline Others not classified & $127(5.9)$ & $63(5.2)$ & $32(5.4)$ & $32(9.0)$ & $76(5.4)$ & $43(3.8)$ & $68(4.0)$ \\
\hline Missing & $66(3.0)$ & $37(3.0)$ & $16(2.7)$ & $13(3.7)$ & $56(4.0)$ & $33(2.9)$ & $49(2.9)$ \\
\hline Parents' mental health & $234(10.8)$ & $116(9.5)$ & $63(10.6)$ & $55(15.5)$ & $84(5.9)$ & $98(8.7)$ & $153(9.0)$ \\
\hline Prior own mental diagnosis & $39(1.8)$ & $20(1.6)$ & $8(1.3)$ & $11(3.1)$ & $33(2.3)$ & $12(1.1)$ & $15(0.9)$ \\
\hline \multicolumn{8}{|l|}{ Non-Crisis $(n=8162)$} \\
\hline $\mathrm{n}$ & $1770(21.7)$ & $1237(15.2)$ & $367(4.5)$ & $166(2.0)$ & $1359(16.7)$ & $1593(19.5)$ & $3440(42.1)$ \\
\hline \multicolumn{8}{|l|}{ Sex } \\
\hline Male & $893(50.5)$ & $630(50.9)$ & $188(51.2)$ & $75(45.2)$ & $701(51.6)$ & $509(32.0)$ & $2057(59.8)$ \\
\hline Female & $877(49.5)$ & $607(49.1)$ & $179(48.8)$ & $91(54.8)$ & $658(48.4)$ & $1084(68.0)$ & $1383(40.2)$ \\
\hline Minimum age at first LFS interview* & $19.5 \pm 1.6$ & $19.4 \pm 1.6$ & $19.8 \pm 1.6$ & $20.1 \pm 1.4$ & $18.8 \pm 1.7$ & $19.2 \pm 1.7$ & $20.0 \pm 1.6$ \\
\hline \multicolumn{8}{|l|}{ Country of birth } \\
\hline Sweden & $1569(88.6)$ & $1106(89.4)$ & $321(87.5)$ & $142(85.5)$ & $1236(91.0)$ & $1476(92.7)$ & $3244(93.7)$ \\
\hline Other & $201(11.4)$ & $131(10.6)$ & $46(12.5)$ & $24(14.5)$ & $123(9.0)$ & $117(7.3)$ & $216(6.3)$ \\
\hline \multicolumn{8}{|l|}{ Parental education } \\
\hline Primary & $782(44.2)$ & $518(41.9)$ & $186(50.7)$ & $78(47.0)$ & $343(25.2)$ & $603(37.9)$ & $1628(47.3)$ \\
\hline Secondary & $635(35.9)$ & $457(36.9)$ & $122(33.2)$ & $56(33.7)$ & $463(34.1)$ & $545(34.2)$ & $1231(35.6)$ \\
\hline University and above & $278(15.7)$ & $216(17.5)$ & $43(11.7)$ & $19(11.5)$ & $501(36.9)$ & $395(24.8)$ & $509(14.8)$ \\
\hline Missing & $74(4.2)$ & $46(3.7)$ & $16(4.4)$ & $13(7.8)$ & $52(3.8)$ & $50(3.1)$ & $72(2.1)$ \\
\hline \multicolumn{8}{|l|}{ Parental SEI } \\
\hline High non-manual & $151(8.5)$ & $127(10.3)$ & $19(5.2)$ & $5(3.0)$ & $309(22.7)$ & $208(13.1)$ & $278(8.1)$ \\
\hline Middle non-manual & $284(16.1)$ & $222(18.0)$ & $41(11.2)$ & $21(12.7)$ & $330(24.3)$ & $322(20.2)$ & $590(17.2)$ \\
\hline Low non-manual & $232(13.1)$ & $161(13.0)$ & $52(14.2)$ & $19(11.5)$ & $176(13.0)$ & $225(14.1)$ & $541(15.2)$ \\
\hline Self-employed/farmer & $173(9.8)$ & $126(10.2)$ & $36(9.8)$ & $11(6.6)$ & $108(8.0)$ & $190(11.9)$ & $472(13.7)$ \\
\hline Skilled workers & $291(16.4)$ & $195(15.8)$ & $68(18.5)$ & $28(16.9)$ & $167(12.3)$ & $235(14.8)$ & $582(16.9)$ \\
\hline Unskilled workers & $409(23.1)$ & $259(20.9)$ & $102(27.8)$ & $48(28.9)$ & $150(11.0)$ & $281(17.6)$ & $722(21.0)$ \\
\hline Others not classified & $159(9.0)$ & $98(7.9)$ & $37(10.1)$ & $24(14.5)$ & $64(4.7)$ & $82(5.2)$ & $188(5.6)$ \\
\hline Missing & $71(4.0)$ & $49(4.0)$ & $12(3.3)$ & $10(6.0)$ & $55(4.1)$ & $50(3.1)$ & $67(2.0)$ \\
\hline Parents' mental health & $218(12.3)$ & $142(11.5)$ & $54(14.7)$ & $22(13.3)$ & $91(6.7)$ & $159(10.0)$ & $327(9.5)$ \\
\hline Prior own mental diagnosis & $56(3.2)$ & $32(2.6)$ & $16(4.4)$ & $8(4.8)$ & $30(2.2)$ & $16(1.0)$ & $37(1.1)$ \\
\hline
\end{tabular}

*Mean values (with SDs) are presented for these measures.

LFS, Labour Force Survey; SEI: socioeconomic index.

Comparing the two cohorts, the parent's level of education and SEI was consistently higher in the crisis cohort compared with the non-crisis cohort. More male individuals were defined as being unemployed in the crisis cohort compared with the non-crisis cohort.
Labour force status and mental diagnosis

Analyses were combined for male and female individuals, since no significant interaction between labour force status and sex was found. Eleven individuals died and were lost to follow-up, the majority was due to fatal accidents and one committed 
suicide. During the follow-up, a total of 557 individuals received inpatient care due to a mental diagnosis, $252(3.9 \%)$ in the crisis cohort and $305(3.7 \%)$ in the non-crisis cohort. In the crisis cohort, the average follow-up time was 17.1 years and 16.8 years in the non-crisis cohort.

In the fully adjusted analysis for the crisis cohort, $<3$ months unemployment (HR: 1.69 , 95\% CI 1.14 to 2.49 ), 3-6 months unemployment (HR: 2.19, 95\% CI 1.43 to 3.37) and $>6$ months unemployment (HR: 2.70 , 95\% CI 1.71 to 4.28 ) was associated with an increased risk of getting a mental diagnosis (table 2). No association was found between being economically inactive or having an unstable labour force status and mental diagnosis. Similar results were seen in the fully adjusted analysis for the non-crisis cohort; $<3$ months unemployment (HR: $1.92,95 \%$ CI 1.40 to 2.63), 3-6 months unemployment (HR: 2.60, 95\% CI 1.72 to 3.94 ) and $>6$ months unemployment (HR: 3.33, 95\% CI 2.00 to 5.57). Further, no association was found between being economically inactive or having an unstable labour force status and mental diagnosis.

\section{Interaction analysis}

After adjusting for prior mental diagnosis, the HRs attenuated marginally more in the non-crisis cohort compared with the crisis cohort (model 2). The interaction between labour force status and level of unemployment in the fully adjusted model was not statistically significant $(p=0.95)$. However, part of the health selection effects could have been removed after adjusting for prior mental health problems, consequently we conducted an additional interaction analysis after adjusting for sex, age and country of birth, which reported similar findings $(p=0.79)$.

\section{Sensitivity analysis}

Poor mental health is a risk factor of unemployment. Thus, we performed a sensitivity analysis excluding the 238 individuals with registered mental health problems prior to participating in the LFS. The sensitivity analysis demonstrated similar effects of unemployment on mental health as in the main analysis (see online supplementary table S1).

\section{Additional analysis}

Additional analyses were performed to explore the effect of unemployment on alcohol and drug use disorders, affective disorders, stress-related disorders and self-harm (table 3). Although the three unemployment groups were combined into one group for this analysis, the results should be interpreted with caution due to few observations in each group. The results suggest that youth unemployment is strongly associated with alcohol and drug use disorders in the crisis cohort (HR: 2.58, 95\% CI 1.43 to 4.65 ) and the non-crisis cohort (HR: 2.34, 95\% CI 1.54 to 3.57). In addition, in the non-crisis cohort unemployment was positively associated with stress-related disorders (HR: 2.08, $95 \%$ CI 1.64 to 4.76 ).

\section{DISCUSSION}

The results of this nationwide study found that youth unemployment was associated with an increased risk of getting a mental diagnosis during a long-term follow-up, irrespective of the overall national rates of unemployment. Further, youth unemployment appears to be strongly associated with alcohol and drug use disorders.

The current results support and further extend the long-term negative consequences of youth unemployment in a number of ways. ${ }^{13}$ First, in line with previous longitudinal studies and meta-analysis on the working-age population, a positive association between youth unemployment and mental diagnosis requiring inpatient care was found. ${ }^{24} 2930$ Previous research has found that youth unemployment is associated with decreased self-reported mental health and well-being. ${ }^{78}{ }^{13}$ Extending previous research on the positive association between youth unemployment and self-reported alcohol consumption and alcohol dependence, ${ }^{9} 12$ the current results suggest an increased risk of being hospitalised for an alcohol or drug use disorder.

Table 2 Crude and adjusted HRs with 95\% Cls for the associations between labour force status and mental diagnosis, stratified by cohort

\begin{tabular}{|c|c|c|c|c|c|c|}
\hline Cohort & $\begin{array}{l}\text { Crude HR } \\
(95 \% \mathrm{Cl})\end{array}$ & $\begin{array}{l}\text { Model } 1 \\
\text { HR adjusted } \\
(95 \% \mathrm{Cl})\end{array}$ & $\begin{array}{l}\text { Model } 2 \\
\text { HR adjusted } \\
(95 \% \mathrm{Cl})\end{array}$ & $\begin{array}{l}\text { Model } 3 \\
\text { HR adjusted } \\
(95 \% \mathrm{Cl})\end{array}$ & $\begin{array}{l}\text { Model } 4 \\
\text { HR adjusted } \\
(95 \% \mathrm{Cl})\end{array}$ & $\begin{array}{l}\text { Number of individuals } \\
\text { with mental diagnosis/ } \\
\text { number of individuals (\%) }\end{array}$ \\
\hline \multicolumn{7}{|l|}{ Crisis } \\
\hline Full-time worker (ref) & 1.0 & 1.0 & 1.0 & 1.0 & 1.0 & $50 / 1698(2.5)$ \\
\hline \multicolumn{7}{|l|}{ Unemployed } \\
\hline Less than 3 months & 1.67 (1.15 to 2.44$)$ & 1.74 (1.18 to 2.56$)$ & 1.67 (1.13 to 2.47$)$ & 1.69 (1.14 to 2.49$)$ & 1.69 (1.14 to 2.49$)$ & $59 / 1220(4.8)$ \\
\hline $3-6$ months & 2.21 (1.45 to 3.37$)$ & 2.30 (1.50 to 3.54$)$ & 2.21 (1.44 to 3.40$)$ & 2.20 (1.43 to 3.38$)$ & 2.19 (1.43 to 3.37$)$ & $38 / 596(6.4)$ \\
\hline More than 6 months & 3.08 (1.97 to 4.82$)$ & 3.27 (2.08 to 5.15$)$ & 3.00 (1.90 to 4.73$)$ & 2.81 (1.78 to 4.44$)$ & 2.70 (1.71 to 4.28$)$ & 31/354 (8.6) \\
\hline Economically inactive & $0.92(0.60$ to 1.40$)$ & 0.94 (0.61 to 1.47$)$ & 0.88 (0.57 to 1.38$)$ & $0.94(0.59$ to 1.46$)$ & $0.94(0.60$ to 1.48$)$ & $37 / 1418(2.6)$ \\
\hline Unstable labour force status & $1.14(0.75$ to 1.75$)$ & 1.11 (0.72 to 1.72$)$ & $1.10(0.71$ to 1.70$)$ & $1.13(0.73$ to 1.75$)$ & $1.12(0.72$ to 1.74$)$ & $37 / 1124(3.3)$ \\
\hline \multicolumn{7}{|l|}{ Non-crisis } \\
\hline Full-time worker (ref) & 1.0 & 1.0 & 1.0 & 1.0 & 1.0 & $94 / 3440(2.7)$ \\
\hline \multicolumn{7}{|l|}{ Unemployed } \\
\hline Less than 3 months & 2.06 (1.51 to 2.82$)$ & 2.09 (1.52 to 2.86$)$ & 1.98 (1.44 to 2.72$)$ & 1.94 (1.41 to 2.66$)$ & $1.92(1.40$ to 2.63$)$ & $68 / 1237(5.5)$ \\
\hline $3-6$ months & 3.19 (2.13 to 4.79$)$ & 3.15 (2.09 to 4.74$)$ & 2.78 (1.84 to 4.20$)$ & 2.71 (1.79 to 4.09$)$ & 2.60 (1.72 to 3.94$)$ & $31 / 367(8.4)$ \\
\hline More than 6 months & $4.17(2.52$ to 6.90$)$ & 4.05 (2.44 to 6.72$)$ & $3.50(2.10$ to 5.82$)$ & 3.36 (2.01 to 5.61$)$ & $3.33(2.00$ to 5.57$)$ & $18 / 166(10.8)$ \\
\hline Economically inactive & $1.19(0.83$ to 1.71$)$ & 1.24 (0.86 to 1.80$)$ & 1.19 (0.82 to 1.72$)$ & $1.19(0.82$ to 1.74$)$ & 1.22 (0.83 to 1.77$)$ & $43 / 1359(3.2)$ \\
\hline Unstable labour force status & 1.19 (0.84 to 1.67$)$ & 1.25 (0.88 to 1.78$)$ & 1.24 (0.87 to 1.76$)$ & 1.24 (0.87 to 1.77$)$ & 1.24 (0.87 to 1.76$)$ & $51 / 1593(3.2)$ \\
\hline
\end{tabular}


Table 3 Adjusted HRs with $95 \%$ Cls for the associations between labour force status and specific mental diagnosis, stratified by cohort

\begin{tabular}{|c|c|c|c|c|c|c|c|c|}
\hline \multirow[b]{2}{*}{ Cohort } & \multicolumn{2}{|l|}{ Affective* } & \multicolumn{2}{|l|}{ Stress } & \multicolumn{2}{|l|}{ Alcohol/drug use } & \multicolumn{2}{|l|}{ Self-harm } \\
\hline & $\begin{array}{l}\text { HR adjusted } \\
(95 \% \mathrm{Cl})\end{array}$ & $\begin{array}{l}\text { Number of } \\
\text { events }\end{array}$ & $\begin{array}{l}\text { HR adjusted } \\
(95 \% \mathrm{Cl})\end{array}$ & $\begin{array}{l}\text { Number of } \\
\text { events }\end{array}$ & $\begin{array}{l}\text { HR adjusted } \\
(95 \% \mathrm{Cl})\end{array}$ & $\begin{array}{l}\text { Number of } \\
\text { events }\end{array}$ & $\begin{array}{l}\text { HR adjusted } \\
(95 \% \mathrm{Cl})\end{array}$ & $\begin{array}{l}\text { Number of } \\
\text { events }\end{array}$ \\
\hline \multicolumn{9}{|l|}{ Crisis } \\
\hline Full-time worker (ref) & 1.0 & 12 & 1.0 & 17 & 1.0 & 16 & 1.0 & 5 \\
\hline Unemployed (total) & 1.84 (0.92 to 3.68$)$ & 30 & 1.69 (0.94 to 3.06$)$ & 39 & 2.58 (1.43 to 4.65$)$ & 45 & 2.02 (0.69 to 5.85 ) & 14 \\
\hline Economically inactive & 1.32 (0.59 to 2.98$)$ & 15 & $0.93(0.45$ to 1.98$)$ & 14 & $0.57(0.20$ to 1.61$)$ & 5 & $0.78(0.17$ to 3.50$)$ & 3 \\
\hline Unstable labour force status & 1.45 (0.64 to 3.30$)$ & 13 & 0.97 (0.45 to 2.08$)$ & 12 & 0.98 (0.41 to 2.34$)$ & 8 & $1.21(0.31$ to 4.71$)$ & 4 \\
\hline \multicolumn{9}{|l|}{ Non-crisis } \\
\hline Full-time worker (ref) & 1.0 & 24 & 1.0 & 23 & 1.0 & 41 & 1.0 & 6 \\
\hline Unemployed (total) & 1.54 (0.85 to 2.79$)$ & 22 & 2.08 (1.64 to 4.76$)$ & 38 & 2.34 (1.54 to 3.57$)$ & 51 & 1.86 (0.58 to 5.94$)$ & 6 \\
\hline Economically inactive & 1.82 (0.93 to 3.56$)$ & 16 & 1.75 (0.90 to 3.42$)$ & 16 & $0.65(0.32$ to 1.33$)$ & 10 & 0.58 (0.07 to 5.16$)$ & 1 \\
\hline Unstable labour force status & 0.98 (0.47 to 2.05$)$ & 11 & 1.89 (1.02 to 3.49$)$ & 21 & 1.07 (0.60 to 1.93$)$ & 17 & $0.78(0.15$ to 4.02$)$ & 2 \\
\hline
\end{tabular}

Similar to previous research, the length of unemployment appeared to increase the risk of getting a mental diagnosis, which could be an indication of a causal relationship. ${ }^{7} 31$ The results referring to the group of young people unemployed $<3$ months should be interpreted with caution. This group partly contains youths who are in between education and working life, and some long-term unemployed youths that did not participate in all eight interviews, since consecutive unemployment was of interest.

In accordance to previous research, the current results did not find strong evidence that the experience of unemployment changes when the national rate of unemployment fluctuates. ${ }^{19}$ 21-23 Scholars have proposed stronger adverse health effects of becoming unemployed during a period of low unemployment compared with a period of high unemployment. ${ }^{17}$ The potential social and psychological processes that vary with context might, however, be different among youths compared with the middle-aged population. Youths are more likely to seek employment as opposed to becoming unemployed, consequently periods of high unemployment might be more stressful for this group due to the limited employment opportunities. $^{19} 20$

Owing to sampling variability, the proportion of unemployed was high in both cohorts, well above the national unemployment rates at that time. ${ }^{2} 19$ These statistics are based on country averages, thus there could be areas with higher and lower unemployment rates. ${ }^{19}$ Youth tend to pursue a variety of educational and employment pathways, consequently measuring their employment status every 3 months would capture this large variation in their labour force status. This should not have influenced our results as the individuals included in our cohorts experienced unemployment during a period of high and low unemployment, thus any potential influence of context on the health effects of unemployment should remain.

Taking a life course perspective, research suggests that unemployment during youth, a very sensitive time period, can independently effect health later in life. ${ }^{6}{ }^{14-16}$ As a result, changes in prevalence of alcohol consumption and illegal drug use, both risk factors of mental health, during the long-term follow-up should not have much influence on our results. However, the economic crisis in the 1990s directly affected the welfare policy system in Sweden and youths were a very vulnerable group with little social welfare protection and welfare resources available. ${ }^{4}$ Previous research suggests that better financial resources are related to better mental health, thus this change in the welfare resources might potentially have biased our results. ${ }^{19}$

\section{Strengths and limitations}

A long follow-up time, a large sample size and register-based linkage are major strengths. The exposure was well defined and measured prospectively at repeated assessment points with a 3 -month interval. Previous research has relied on retrospectively collected data on employment status either yearly, 5 years or up to 10 years in between each interview. ${ }^{810}$ The employment statuses in the LFS are based on numerous questions, in order to minimise misclassification. As the LFS is used to obtain the official labour force statistics in Sweden, the individuals categorised as unemployed are defined in accordance with European definition of unemployment set by Eurostat. ${ }^{26} 27$

The outcome of mental diagnosis was collected from highquality and reliable registers decreasing the risk of biased selfreported results and attrition. Previous research has to a great extent relied on the General Health Questionnaire. This outcome measure is highly susceptible to bias, especially when repeated measurements are collected. ${ }^{19}{ }^{24}$ For example, research using this measure has found that individuals rated their mental health better when re-employed, compared with before becoming unemployed. ${ }^{19} 24$

A limitation is, however, that the Hospital Discharge Register began in 1964 and reached full coverage with respect to mental health in $1973 .{ }^{32}$ Thus, there might be a lack of coverage in relation to the individual's parent's registered mental diagnosis and their own prior mental diagnosis. Furthermore, in Sweden only a fraction of all individuals with mental health problems require inpatient care, ${ }^{33}$ thus although the outcome of interest was well defined, it only captured a proportion of the potential cases with the most severe mental health problems. Owing to coverage constraints, we were unable to include the outpatient care register. In addition, due to changes within the medical care system in Sweden since the 1990s, there could be several sources of bias in relation to the amount of hospital beds available, the proneness of doctors to refer mental health patients to inpatient care and the health-seeking behaviour of these individuals that could have influenced the results in different directions. $^{34}$ 


\section{CONCLUSION}

Youth unemployment in Sweden was associated with increased risk of mental health problems that needed inpatient care, in times of an economic crisis and when employment rates were substantially lower. This is important at a time when youth unemployment rates are stable on a high level in Sweden.

\section{What is already known on this subject?}

It is known that youth unemployment is associated with self-reported poor mental health, and poor mental health could be a risk factor of unemployment.

\section{What this study adds?}

This study adds that youth unemployment is a long-term risk factor for hospitalisation for a mental diagnosis independently of the overall national rate of unemployment.

Acknowledgements Statistician Per Tynelius, Department of Public Health Sciences, Karolinska Institutet, provided valuable help with the data files.

Contributors FR conceived the study. ET conducted the statistical analysis and provided the first draft of the manuscript. All authors provided substantial editing to the final manuscript.

Funding This work was supported by a grant to Finn Rasmussen from the Swedish Research Council for Health, Working Life, and Welfare with contract number 2014-2009.

Competing interests None declared.

Ethics approval The study was approved by the Stockholm Regional Ethical Review Board (Dnr: 2016/112-31).

Provenance and peer review Not commissioned; externally peer reviewed.

Open Access This is an Open Access article distributed in accordance with the Creative Commons Attribution Non Commercial (CC BY-NC 4.0) license, which permits others to distribute, remix, adapt, build upon this work non-commercially, and license their derivative works on different terms, provided the original work is properly cited and the use is non-commercial. See: http://creativecommons.org/ licenses/by-nc/4.0/

\section{REFERENCES}

1 International Labour Organization. Global employment trends in youth 2015: Scaling up investments in decent jobs for youth. Geneva: International Labour Office, 2015

2 Statistics Sweden. Arbetskraftsundersökningarna 1980-1990 (Labour Force Survey 1980-1990). Stockholm, Sweden: Statistics Sweden, Statistiska meddelanden., Serie Am, 1991 (In Swedish).

3 Bergmark $\AA$, Palme J. Welfare and the unemployment crisis: Sweden in the 1990s. Int J Soc Wel 2003;12:108-22.

4 Bell DN, Blanchflower DG. Young people and the great recession. Oxford Review of Economic Policy 2011;27:241-67.

5 OECD. OECD Employment Outlook 20152015.

6 Viner RM, Ross D, Hardy R, et al. Life course epidemiology: recognising the importance of adolescence. J Epidemiol Community Health 2015:69:719-20.

7 Hammer T. Unemployment and mental health among young people: a longitudinal study. J Adolesc 1993;16:407-20.
8 Hammarström A, Janlert U. Nervous and depressive symptoms in a longitudinal study of youth unemployment-selection or exposure? J Adolesc 1997;20:293-305.

9 Fergusson DM, Horwood LJ, Lynskey MT. The effects of unemployment on psychiatric illness during young adulthood. Psychol Med 1997;27:371-81.

10 Montgomery SM, Cook DG, Bartley MJ, et al. Unemployment pre-dates symptoms of depression and anxiety resulting in medical consultation in young men. Int J Epidemiol 1999:28:95-100.

11 Fergusson DM, Horwood LJ, Woodward LJ. Unemployment and psychosocial adjustment in young adults: causation or selection? Soc Sci Med 2001:53:305-20.

12 Janlert U, Hammarström A. Alcohol consumption among unemployed youths: results from a prospective study. Br J Addicti 1992;87:703-14.

13 Reneflot A, Evensen M. Unemployment and psychological distress among young adults in the Nordic countries: a review of the literature. Int I Soc Wel 2014;23:3-15.

14 Fergusson DM, McLeod GF, Horwood LJ. Unemployment and psychosocial outcomes to age 30: a fixed-effects regression analysis. Aust N Z J Psychiatry 2014:48:735-42.

15 Strandh M, Winefield A, Nilsson K, et al. Unemployment and mental health scarring during the life course. Eur J Public Health 2014;24:440-5.

16 Hammarström A, Janlert U. Early unemployment can contribute to adult health problems: results from a longitudinal study of school leavers. J Epidemiol Community Health 2002:56:624-30.

17 Martikainen PT, Valkonen T. Excess mortality of unemployed men and women during a period of rapidly increasing unemployment. Lancet 1996;348:909-12.

18 Clark AE. Unemployment as a social norm: psychological evidence from panel data. J Labor Econ 2003;21:323-51.

19 McKee-Ryan F, Song Z, Wanberg CR, et al. Psychological and physical well-being during unemployment: a meta-analytic study. J App/ Psychol 2005;90:53.

20 Frasquilho D, Matos MG, Salonna F, et al. Mental health outcomes in times of economic recession: a systematic literature review. BMC Public Health 2016;16:115.

21 Novo M, Hammarström A, Janlert U. Health hazards of unemployment-only a boom phenomenon? A study of young men and women during times of prosperity and times of recession. Public Health 2000;114:25-9.

22 Beland F, Birch S, Stoddart G. Unemployment and health: contextual-level influences on the production of health in populations. Soc Sci Med 2002;55:2033-52.

23 Strandh M, Novo M, Hammarström A. Mental health among the unemployed and the unemployment rate in the municipality. Eur J Public Health 2011;21:799-805.

24 Paul Kl, Moser K. Unemployment impairs mental health: meta-analyses. J Vocat Behav 2009:74:264-82.

25 Statistics Sweden. Tidigare Folk-och bostadsräkningar (FoB) 1960-1990 (National Population and Housing Censuses 1960-1990). Örebro: SCB, 2001. (In Swedish).

26 Statistics Sweden. Arbetskraftsundersökningarna 1985-1994: Befolkningen i åldern 16-64 år (Labour Force Survey 1985-1994). Stockholm, Sweden: Statsitics Sweden, Statistiska meddelanden., Serie Am, 1995. (In Swedish).

27 Statistics Sweden. Ungdomsarbetslöshet-jämförbarhet i statistiken mellan ett antal europeiska länder (Youth unemployment-comparability in statistics between a number of European countries). Stockholm, Sweden 2013. Report No.: 4. (In Swedish).

28 Statistics Sweden. Multi-generation register 2010: a description of contents and quality. 2011.

29 Hollander AC, Bruce D, Ekberg J, et al. Hospitalisation for depressive disorder following unemployment-differentials by gender and immigrant status: a population-based cohort study in Sweden. J Epidemiol Community Health 2013;67:875-81.

30 Eliason M, Storrie D. Inpatient psychiatric hospitalization following involuntary job loss. Int J Ment Health 2010;39:32-55.

31 Hill $A B$. The environment and disease: association or causation? Proc $R$ Soc Med 1965;58:295.

32 Socialstyrelsen. Kvalitet och innehåll i patientregistret (The quality and content of The National Patient Register). Stockholm: Socialstyrelsen: Epidemiologiska centrum, 2009 (In Swedish)

33 Folkhälsomyndigheten. Folkhälsa i Sverige (Public health in Sweden). Stockholm Sweden, 2014 (In Swedish)

34 Anell A, Glenngård AH, Merkur S. Sweden: Health system review. Health Systems in Transition 2012;14:1-159. 